\title{
Epidemiological revision of high fertility behaviors among mothers in Mosul city, Iraq
}

\begin{tabular}{|c|c|c|}
\hline Asma A. Aljawadi* & Hajir H. Al-Ridhwany** & Muthanna S. Abduljawad** \\
\hline & Abstract & \\
\hline
\end{tabular}

Background and objective: Collective high fertility behaviors is a term that refers to mothers who had got married during their teenage and having parity of five or more living children with less than 24 months apart. The present study aimed to estimate the prevalence of collective high fertility behaviors among mothers in Mosul city, Iraq.

Methods: A cross-sectional study was carried out using a multi-stage stratified sampling method. Inclusion criteria included mothers in child-bearing age who had at least two living children. The required data were collected by filling an especially structured questionnaire in the eligible primary health care centers over a period of ten months, from April, $1^{\text {st }} 2011$ to the end of January 2012.

Results: Among 1302 participants, the prevalence of high fertility behaviors was $17.7 \%$ within all age groups. The prevalence was significantly higher among Muslim, low social classes $(P<0.001)$, nuclear family structure $(P<0.001)$, consanguineous marriage $(P<0.001)$ and low educated mothers and husbands $(P<0.001)$.

Conclusion: The study found that collective high fertility behaviors are prevalent among almost two out of ten mothers of all age groups in Mosul city. Thus, effective engagement of all human resources is recommended for constructing healthy fertility behaviors and confirming the non-reproductive role of women.

Keywords: Epidemiological; Fertility; Behaviors; Prevalence; Mothers.

\section{Introduction}

Fertility is one of three principal components of population dynamics that determine population size and structure of a country. ${ }^{1}$ It is a product of the interaction of a complex set of factors, which include: biological, cultural, demographical, familial and social factors. ${ }^{2}$ Basically, fertility is determined by the underlying socioeconomic conditions through an influence on the proximate (immediate) determinants. The later bridges the basic determinants of fertility with the realized fertility behaviors to shape fertility levels. These proximate determinants include the extent of exposure to the union (i.e., age at marriage and age at starting reproduction), fecund-ability which is the probability of pregnancy per month (including desired and achieved a number of children) and duration of postpartum unproductiveness, i.e. birth spacing. ${ }^{3}$ The World Health Organization has defined teenage pregnancies as a pregnancy in a young woman who has not reached her $20^{\text {th }}$ birthday (before completing the nineteen years old). ${ }^{4}$ Pregnant teenagers face the same obstetrics issues as women in their 20s and 30s. Mothers aging 14 years or younger, especially if they live in a developing country, face additional medical concerns such as several types of nutritional deficiencies and anemia ${ }^{5}$ as well as many other social problems as higher rates of drop-out of school and poverty. ${ }^{6}$ Additionally, high birth rates and short inter -pregnancy interval, which are considered as major determinants of fertility levels in high fertility populations, have been associated with health impairments, low

* Department of Family and Community Medicine, College of Medicine, University of Mosul, Nineveh, I raq ** Nineveh Health Directorate, Nineveh, I raq. 
living standards, and low levels of education. It can also stress on the government to support the growing youthful population. ${ }^{7}$ The present study aimed to estimate the prevalence of collective high fertility behavior among a sample of mothers attending primary health care centers in Mosul city and determine the association between socio-demographic characteristics' with such behavior.

\section{Methods}

Administrative and ethical agreements were obtained from Nineveh Health Directorate to conduct a cross-sectional study design in Mosul city-Iraq. The study followed a multi-stage stratified sampling method in order to confirm the representativeness of the studied sample. By the first stage, Mosul city is divided vertically by Tigris River and horizontally by Nineveh Street and its extension into four geographical areas: northeast, north-west, south-east, and south-west. Each area had been classified into three social strata according to its closeness to downtown: urban, peri-urban (points to the areas located at the periphery of the city center) and rural. Within each area, five primary health care centers (PHCCs) were selected conveniently depending on the highest population size and proportion of women in the child-bearing age in each catchment area. The included twenty PHCCs represented $70 \%$ of all health centers in Mosul city. Inclusion criteria were currently married mothers in child-bearing age who had at least two living children. Eligible mothers were selected consecutively after obtaining verbal consents from them. Presence of at least one of the following criteria indicated high fertility behaviors:

* The teenage marriage of mother, i.e. before the age of twenty.

* High parity, i.e. having five or more living children

* Short birth spacing, i.e. birth-to-pregnancy (BTP) intervals are less than 24 months.

Thus the studied sample was divided into three groups: mothers with all the above criteria collectively, they were reported as having collective high fertility behaviors (CHFBs), mothers who had not practiced any of such behaviors and mothers with at least one of these behaviors but did not accomplish the criteria of CHFBs. A convenience sample of 1302 married mothers with inclusion criteria was selected. Distribution of the estimated sample was weighted according to population size and proportion of married women in a child-bearing age in each catchment area. A specially designed questionnaire was used to address all relevant mothers' demographic characteristics. It inquired about the actual fertility behaviors of the mothers including their age at marriage, number of living children and interval between their births. The validity of the questionnaire was assessed by Angoff approach as $83.8 \%$. A pilot study was conducted before practicing the questionnaire form in order to construct an appropriate and informative edition of the adopted questionnaire; assess the reliability and to estimate the time needed for completing data collection. Both intro- and inter-observer's variations were estimated as $86.8 \%$ and $82.9 \%$ respectively that made the questionnaire's reliability $87.2 \%$. The study was carried out from the 1st of April 2011 to the end of January 2012. The work schedule was organized to visit each geographical area once every fourth week. The first area was selected randomly, and the remaining were arranged systematically in a clockwise direction. Through each week, five PHCCs were visited from Sunday to Thursday; and 8-12 mothers were met per a visit. Statistical analysis was applied to estimate the prevalence of CHFBs among the studied sample in general, and among each studied factor in specific. The associated socio-demographic and cultural factors were determined by applying the Chi-square test. $P$ value was considered significant when it was equal to or less than 0.05 throughout the analysis. 


\section{Results}

The present study included 1302 mothers who met the inclusion criteria. They were either derived from urban areas $(52.4 \%)$ or periurban and rural settings $(47.6 \%)$. The majority were Muslim $(93.9 \%)$. They were of different ethnic groups; $83.7 \%$ were Arabs, $7.3 \%$ were Kurds, $4.8 \%$ were Turkmen, and $4.1 \%$ were Shabaks. The mean age of studied mothers was $30.0 \pm 7.7$ years. Most of them $(70.3 \%)$ were in their twenties or thirties.
Only $7.4 \%$ were younger than 20 years old, while $12.3 \%$ were in the age group $40-49$ years (Table 1). It was reported that 231 women experienced high fertility behaviors collectively, making the prevalence of collective high fertility behaviors (CHFBs) in Mosul city $17.7 \%$. In turn, 152 mothers $(11.7 \%)$ did not practice any of such behaviors. The rest of the studied mothers (919) recorded at least one these behaviors $(70.6 \%)$ as shown in Figure 1.

Table 1: General characteristics of studied families.

\begin{tabular}{|c|c|c|c|c|c|c|c|}
\hline \multirow[t]{2}{*}{ General characteristics } & \multicolumn{2}{|c|}{$\begin{array}{c}\text { Urban } \\
\mathrm{n}=682(52.4 \%)\end{array}$} & \multicolumn{2}{|c|}{$\begin{array}{l}\text { Peri-urban \& rural } \\
n=620(47.6 \%)\end{array}$} & \multicolumn{2}{|c|}{$\begin{array}{c}\text { Total } \\
(\mathrm{N}=1302)\end{array}$} & \multirow[t]{2}{*}{$P$ value } \\
\hline & No. & (\%) & No. & (\%) & No. & (\%) & \\
\hline \multicolumn{8}{|l|}{ Religion } \\
\hline Muslims & 631 & $(92.5)$ & 592 & $(95.5)$ & 1223 & $(93.9)$ & \multirow[b]{2}{*}{0.025} \\
\hline Christians & 51 & $(7.5)$ & 28 & $(4.5)$ & 79 & (6.1) & \\
\hline \multicolumn{8}{|l|}{ Ethnicity } \\
\hline Arab & 621 & $(91.0)$ & 469 & $(75.5)$ & 1090 & $(83.7)$ & \multirow{4}{*}{$<0.001$} \\
\hline Kurd & 32 & $(4.7)$ & 63 & $(10.2)$ & 95 & (7.3) & \\
\hline Turkmen & 23 & (3.4) & 40 & (6.5) & 63 & $(4.8)$ & \\
\hline Shabak & 6 & $(0.9)$ & 48 & $(7.7)$ & 54 & $(4.1)$ & \\
\hline \multicolumn{8}{|l|}{ Age (in years) } \\
\hline$<20$ & 60 & $(8.8)$ & 36 & $(5.8)$ & 96 & $(7.4)$ & \multirow{4}{*}{0.059} \\
\hline $20-29$ & 298 & $(43.7)$ & 251 & $(40.5)$ & 549 & $(42.2)$ & \\
\hline $30-39$ & 242 & $(35.5)$ & 254 & $(41.0)$ & 496 & $(38.1)$ & \\
\hline $40-49$ & 82 & $(12.0)$ & 79 & $(12.7)$ & 161 & (12.3) & \\
\hline
\end{tabular}

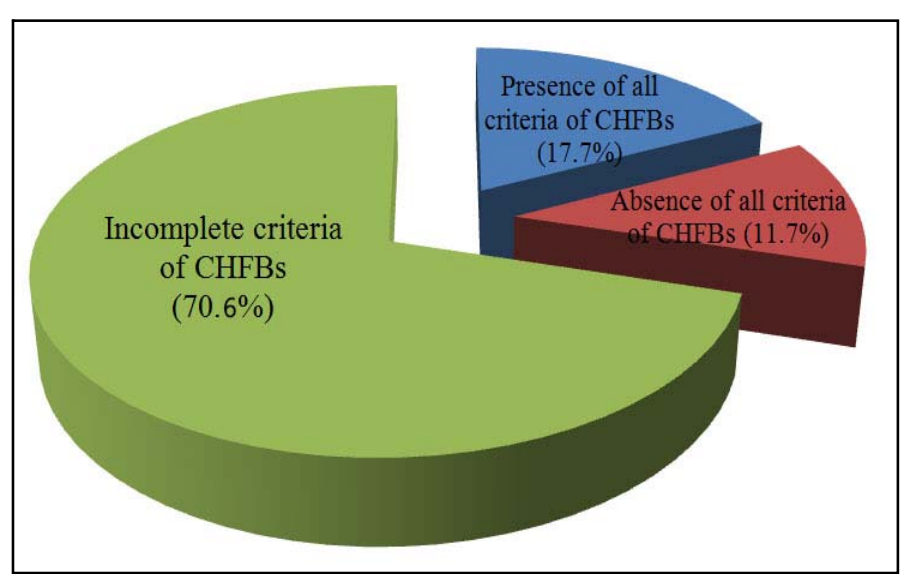

Figure 1: Distribution of CHFBs among the studied mothers. 
Table 2 shows the association of the prevalent CHFBs with the sociodemographic features of the studied families. Prevalence of CHFBs was higher among Muslim mothers whereas it was not recorded among the Christian families. At the same time, the absence of CHFBs was found among $10.4 \%$ of Muslims in opposite to $16.5 \%$ of the Christian sample. A quarter of Kurd mothers (24.2\%) practiced CHFBs. However, it is significantly lower than that recorded among other ethnic groups (33.3\% among Shabak and 58.7\% among Turkmeni mothers) $(P<0.001)$. The same pictures were seen regarding the absence of all high fertility behaviors, i.e. Kurd families recorded the highest rate $(30.5 \%)$.
Urban mothers were significantly less prone to record CHFBs (12.0\%) than peri-urban and rural mothers $(24.0 \%)$ $(P<0.001)$. The inverted picture was affirmed among urbanized mothers who had the highest rate of CHFBs $(80.5 \%)$ $(P<0.001)$. Urbanization is moving from rural to urban settings within the last ten years. Collective high fertility behaviors were not reported among mothers of high social class, and half of such group $(50.0 \%)$ recorded absence of all forms CHFBs. In addition, just $12.1 \%$ of $3^{\text {rd }}$ social class mothers recorded CHFBs $(P<0.001)$. While mothers derived from fourth and fifth social classes significantly experienced CHFBs as twice as other mothers.

Table 2: Association of CHFBs with socio-demographic features of the studied sample.

\begin{tabular}{|c|c|c|c|c|c|c|c|c|}
\hline \multirow{3}{*}{$\begin{array}{l}\text { Socio-demographic } \\
\text { features }\end{array}$} & \multicolumn{6}{|c|}{ CHFBs } & \multirow{3}{*}{$C h i^{2}$} & \multirow{3}{*}{$P$ value } \\
\hline & \multicolumn{2}{|c|}{$\begin{array}{l}\text { Present } \\
(n=231)\end{array}$} & \multicolumn{2}{|c|}{$\begin{array}{l}\text { Incomplete } \\
(n=919)\end{array}$} & \multicolumn{2}{|c|}{$\begin{array}{l}\text { Absent } \\
(n=152)\end{array}$} & & \\
\hline & No. & (\%) & No. & (\%) & No. & (\%) & & \\
\hline \multicolumn{9}{|l|}{ Religion } \\
\hline Muslim & 231 & $(18.9)$ & 865 & 70.7 & 127 & $(10.4)$ & \multirow[b]{2}{*}{ NA } & \multirow[b]{2}{*}{ NA } \\
\hline Christian & 0 & $(0.0)$ & 66 & 83.5 & 13 & $(16.5)$ & & \\
\hline \multicolumn{9}{|l|}{ Ethnicity } \\
\hline Arab & 153 & $(14.0)$ & 841 & $(77.2)$ & 96 & $(8.8)$ & \multirow{4}{*}{174.5} & \multirow{4}{*}{$<0.001$} \\
\hline Kurd & 23 & $(24.2)$ & 43 & $(45.3)$ & 29 & $(30.5)$ & & \\
\hline Turkmen & 37 & $(58.7)$ & 15 & $(23.8)$ & 11 & $(17.5)$ & & \\
\hline Shabak & 18 & $(33.3)$ & 20 & $(37.1)$ & 16 & $(29.6)$ & & \\
\hline \multicolumn{9}{|l|}{ Residence } \\
\hline Urban & 82 & $(12.0)$ & 518 & $(76.0)$ & 82 & $(12.0)$ & \multirow[b]{2}{*}{32.4} & \multirow[b]{2}{*}{$<0.001$} \\
\hline Suburban and rural & 149 & $(24.0)$ & 401 & $(64.7)$ & 70 & (11.3) & & \\
\hline \multicolumn{9}{|l|}{ Urbanization } \\
\hline Present & 157 & $(80.5)$ & 14 & $(7.2)$ & 24 & $(12.3)$ & \multirow[b]{2}{*}{640} & \multirow[b]{2}{*}{$<0.001$} \\
\hline Absent & 74 & $(6.7)$ & 905 & $(81.8)$ & 128 & $(11.6)$ & & \\
\hline \multicolumn{9}{|l|}{ Social class } \\
\hline 1st \& 2nd classes* & 0 & $(0.0)$ & 24 & $(50.0)$ & 24 & $(50.0)$ & \multirow{4}{*}{41.7} & \multirow{4}{*}{$<0.001$} \\
\hline 3rd class & 76 & $(12.1)$ & 486 & $(77.4)$ & 66 & $(10.5)$ & & \\
\hline 4th \& 5th classes & 119 & $(23.2)$ & 348 & $(67.7)$ & 47 & $(9.1)$ & & \\
\hline Unemployed & 36 & $(32.1)$ & 61 & $(54.5)$ & 15 & $(13.4)$ & & \\
\hline
\end{tabular}


Table 3 displays the association of CHFBs with structural features of families. It indicates that $27.7 \%$ of mothers of nuclear family structure and $19.7 \%$ of mothers with consanguineous marriage practiced CHFBs $(P<0.001)$. However, the absence of CHFBs was found among the only tenth of mothers with extended family structure $(10.1 \%)$ in comparison to $13.9 \%$ of mothers with nuclear structure $(P<0.001)$. Similarly, a fraction of mothers who experienced CHFBs was significantly higher among mothers married to consanguineous spouses $(19.7 \%)$ in opposite to $14.0 \%$ of mothers without such structural features $(P<0.001)$.

Table 3: Association of CHFBs with structural features of families.

\section{CHFBs}

Structural features $\quad \begin{gathered}\text { Complete } \\ (n=231)\end{gathered} \quad \begin{gathered}\text { Incomplete } \\ (n=919)\end{gathered} \quad \begin{gathered}\text { Absent } \\ (n=152)\end{gathered} \quad C^{2} i^{2} \quad P$ value

No. (\%) No. (\%) No. (\%)

\section{Family structure}

Nuclear

150

$(27.7)$

316

(58.4) $\quad 75$

Extended

$81 \quad(10.6) \quad 603$

$(79.3$

$77 \quad(10.1)$

$75.2<0.001$

\section{Consanguineous marriage}

$\begin{array}{llllllllll}\text { Present } & 168 & (19.7) & 607 & (71.3) & 77 & (9.0) & & \\ \text { Absent } & 63 & (14.0) & 312 & (69.3) & 75 & (16.7) & 20.3 & <0.001\end{array}$

\section{Polygyny}

$\begin{array}{lcccccccc}\text { Present } & 33 & (34.7) & 42 & (44.2) & 20 & (21.1) & & \\ \text { Absent } & 198 & (16.4) & 877 & (72.7) & 132 & (10.9) & & \end{array}$


The association of CHFBs with personal characteristics of the spouses is shown in Table 4. The prevalence was higher among older and working mothers $(27.4 \%$ and $38.4 \%$ respectively, $P<0.001$ and $P<0.001$ in order). However, none of the mothers with 12 years of schooling or higher experienced CHFBs. Moreover, a third of such mothers $(36.1 \%)$ recorded the absence of all aspects of high fertility behaviors. Although CHFBs were significantly less likely to be found among mothers with young husbands $(5.6 \%)$ $(P<0.001)$, paternal marriage before completing 25 years associated with a higher prevalence rate $(30.7 \%)$. Conversely, the absence of CHFBs was recorded among $14.8 \%$ of mothers married to husbands older than 25 years in contrast to $7.3 \%$ of mothers whose husbands were younger at marriage $(P<0.001)$. Wives of low educated husbands, i.e. below 12-years schooling more frequently practiced CHFBs $(17.9 \%)$ than mothers of higher educated husbands $(P<0.001)$. One-fifth of mothers whose husbands had 12 years schooling or higher $(21.0 \%)$ did not practice any of high fertility behaviors in comparison to $9.4 \%$ of mothers of less educated husbands.

Table 4: Association of CHFBs with personal characteristics of the spouses.

\begin{tabular}{|c|c|c|c|c|c|c|c|c|}
\hline \multirow{3}{*}{$\begin{array}{l}\text { Personal } \\
\text { characteristics }\end{array}$} & \multicolumn{6}{|c|}{ CHFBs } & \multirow{3}{*}{$\mathrm{Chi}^{2}$} & \multirow{3}{*}{$P$ value } \\
\hline & \multicolumn{2}{|c|}{$\begin{array}{l}\text { Present } \\
(n=231)\end{array}$} & \multicolumn{2}{|c|}{$\begin{array}{c}\text { Incomplete } \\
(n=919)\end{array}$} & \multicolumn{2}{|c|}{$\begin{array}{l}\text { Absent } \\
(n=152)\end{array}$} & & \\
\hline & No. & (\%) & No. & (\%) & No. & (\%) & & \\
\hline \multicolumn{9}{|c|}{ Maternal age (years) } \\
\hline$<30$ & 51 & (7.9) & 557 & $(86.4)$ & 37 & $(5.7)$ & \multirow[b]{2}{*}{153.3} & \multirow[b]{2}{*}{$<0.001$} \\
\hline$\geq 30$ & 180 & $(27.4)$ & 362 & $(55.1)$ & 115 & $(17.5)$ & & \\
\hline \multicolumn{9}{|c|}{ Maternal education (years of schooling) } \\
\hline$<12$ & 231 & $(18.9)$ & 366 & $(71.1)$ & 122 & $(10.0)$ & \multirow[b]{2}{*}{ NA } & \multirow[b]{2}{*}{ NA } \\
\hline$\geq 12$ & 0 & $(0.0)$ & 53 & $(63.9)$ & 30 & $(36.1)$ & & \\
\hline \multicolumn{9}{|c|}{ Maternal occupation888 } \\
\hline Housewives & 193 & $(16.0)$ & 888 & $(73.8)$ & 122 & $(10.1)$ & \multirow[b]{2}{*}{81.0} & \multirow[b]{2}{*}{$<0.001$} \\
\hline Working & 38 & $(38.4)$ & 31 & $(31.3)$ & 30 & $(30.3)$ & & \\
\hline \multicolumn{9}{|c|}{ Paternal age (years) } \\
\hline$<30$ & 18 & $(5.6)$ & 271 & $(84.7)$ & 31 & $(9.7)$ & \multirow[b]{2}{*}{48.5} & \multirow[b]{2}{*}{$<0.001$} \\
\hline$\geq 30$ & 213 & $(21.7)$ & 648 & $(66.0)$ & 121 & $(12.3)$ & & \\
\hline \multicolumn{9}{|c|}{ Paternal age at marriage (years) } \\
\hline$<25$ & 165 & $(30.7)$ & 333 & $(62.0)$ & 39 & (7.3) & \multirow[b]{2}{*}{111.6} & \multirow[b]{2}{*}{$<0.001$} \\
\hline$\geq 25$ & 66 & (8.6) & 586 & $(76.6)$ & 113 & $(14.8)$ & & \\
\hline \multicolumn{9}{|c|}{ Paternal education (years of schooling) } \\
\hline$<12$ & 187 & $(17.9)$ & 760 & $(72.7)$ & 98 & (9.4) & \multirow[b]{2}{*}{27.4} & \multirow[b]{2}{*}{$<0.001$} \\
\hline$\geq 12$ & 44 & $(17.1)$ & 159 & $(61.9)$ & 54 & $(21.0)$ & & \\
\hline
\end{tabular}




\section{Discussion}

The term "CHFBs" (Collective High Fertility Behaviours) is emerged from the present study to refer to mothers who had got married during their teenage and having parity of five or more living children with less than 24 months in between. The present study showed that the prevalence of CHFBs among mothers attending PHCCs was $17.7 \%$ and was completely omitted by one out of ten mother's (11.7\%). The current study adopted a cross-section study. Such a design has the advantage of being fairly quick and easy to perform. ${ }^{9,12}$ So far, there is no cross-sectional study free of recall biases which may perhaps lead to some alteration of the conclusions. ${ }^{13}$ However, the adopted questionnaire form of the present study was especially structured in a design to minimize such bias. The other and the most important dilemma that may come up with cross-section study design is selection bias. Subjects in health-institutions are more accessible for an interview as well as more cooperative with investigators than persons in the community. Such a sample is more frequently associated with selection bias. $^{13}$ However, efforts were devoted to the present study to ensure representativeness by adopting a multistage stratified sampling technique to include all social strata distributed in the urban, peri-urban and rural setting. It is probably the first time in our locality to address such a subject. So that analog data are not available for comparison. This is certainly apart from studies that concern with each behavior independently. The obtained result is harmonious to some extent with that recorded by the social and health indicators survey of Iraqi women $(\mathrm{I}-\mathrm{WISH})^{14}$ in 2011 which reported that $14.3 \%$ of married women aged $15-49$ years had started their reproduction before completing 18 years old. This figure was higher in rural settings $(15.3 \%)$ than in urban areas $(13.8 \%)$, and it was lower in Kurdistan $(5.9 \%)$ than other Iraqi areas $(15.8 \%)$. In addition, I-WISH found that women aged 45-49 years had on average five living children and rural as well as loweducated women actually had additional two and three children respectively. The minor dissimilarity between findings of the present study and that of I-WISH may be attributed to the different sample frame. The former was based on healthinstitutions in contrast to I-WISH that was a community-based study. ${ }^{12}$ The present study found that CHFBs were significantly less prevalent among urban mothers ( $P$ $<0.001)$. However, urbanization greatly inflated the practice of such behaviors $(P<0.001)$. This trend might have followed allotment of consanguineous marriage $(P<0.001)$ as Fuster $^{15}$ in 2003 , and Helgason et al. ${ }^{16}$ in 2008 found that consanguineous couples, in general, experienced higher fertility rate. A similar conclusion can be assumed within the Arab world. Al-Abdulkareem and Ballal ${ }^{17}$ investigated consanguineous marriages in an urban area of Saudi Arabia. They found that the rate of consanguineous marriage was $52.0 \%$ and the consanguineous groups had a significantly higher number of pregnancies $(P=0.03)$. As well, Hammami et al. $^{18}$ stated in 2005 that Mauritanian consanguineous couples had an average of fertility significantly higher than those of non-consanguineous couples. The same association was noted in Kuwait, Qatar, Beirut, and Tunisia where all recorded significantly higher rates of total pregnancies, live births, and living children among consanguineous couples than among non-consanguineous ones. ${ }^{19-22}$ However, Grant et al. ${ }^{23}$ in 2002 tended to think that such association of fertility and inbreeding could be a biological means of compensating for the increased risk of postnatal loss expected in related marriages or possibly to the earlier age at marriage, earlier first maternity and longer reproductive span among consanguineous as compared to non-consanguineous couples. The present study also indicated that Muslim mothers were more prone to practice CHFBs. The role of religion is 
broached by Iranian experience that witnessed one of the most successful family planning programs in the world. Vahidnia $^{24}$ in 2007 stated that Iran recorded $64 \%$ decline in fertility rate together with $74 \%$ contraceptive use among married women between 1986 and 2000. Such a trend has been achieved merely by recognition of the sensitive moral and ethical aspects of the concerned issues and successful collaboration of technical experts and religious leaders. $\mathrm{He}$ added that full support of religious and community leaders, a well-established primary health care infrastructure and intelligent resource allocation, resulted in a rapid decline in fertility and population growth. Vahidnia also affirmed that this trend had a positive impact on women's health, education, and human development, and will help preserve natural resources for future generations. Moreover, Burner $^{25}$ in 2012 who studied religiousness and fertility among Muslims in Europe found a strong positive association between high fertility behaviors and levels of religiousness among Muslims, Catholics and Protestants when compared with families with no religious affiliation; yet, the highest fertility was among Muslims. The writer stated that although the available data indicated that the fertility of Muslim women is declining, the fertility of Muslims was higher than that of members of the dominant religion; and that fertility of immigrants from Muslim countries is higher than that of the native European population. He also stated that more religious women have more children than those less religious. A similar finding was suggested by $\operatorname{Karim}^{26}$ who based his judgment on the data of Demographic and Health Survey-2005 in India, Pakistan, and Bangladesh. He found that Muslims tended to have higher fertility rates than those in other religious groups. However, fertility started to decline in the mid-1980s in many Muslim countries as a result of effective family planning programs. Thus Karim suggested that socioeconomic conditions and policies have the main impact on the average family size than religion. The present study found that none of the mothers who completed 12-years schooling experienced CHFBs and more than one-third of such mothers (36.1\%) recorded the absence of all facets of high fertility behaviors. Furthermore, mothers whose husbands had a lower level of education, i.e., below 12-years schooling, were more prone to twice as mothers of higher educated husbands to practice CHFBs $(P<0.001)$. As an axiom outcome, the lower the social class, the more the probability of experiencing CHFBs was recorded $(P<0.001)$. Such a trend may be intermediated by early marriage which was proved to raise the presence of CHFBs $(P<0.001)$. Such findings resonate with that of Khraif's ${ }^{27}$ in 2001 . The later found that education is strongly related to fertility in Saudi Arabia where illiterate women tend to have a larger number of children than those with a higher level of education. Illiterate Saudi women were found to have more than six children on average, while a woman who obtained a university degree had less than three children. In the same vein but to a lesser extent, Khraif's added, the higher the level of husband's education is, the smaller the number of children a woman has. León ${ }^{28}$ in 2004 quantified the effects of schooling on fertility decline and recorded that about a quarter of the fertility decline in Germany, Italy, and Ireland, a third of the drop in Portugal and Spain, and as much as half of the fall in Greece can be attributed to the effect of rising female education. In general, the forty years between 1960 and 2000 witnessed widespread dramatic fertility declines accompanied by an increase in educational attainment levels. Fertility rates in every developed nation where the population becomes more educated and the number of children per woman falls are now below the replacement rate of 2.1, ranging from 2.0 in the United States to 1.6 in France and Canada, 1.4 in Japan, and just 1.2 in Italy. In addition, Ayoub et al. ${ }^{29}$ 
in 2007 examined the effects of education on fertility in Colombia and Peru as Latin American countries. They demonstrated that education and fertility remain inversely related to the relationship between education and wage levels. At the same time, they suggested that education may depress fertility for reasons other than micro-economic factors since education improves access for means of empowering women and creating a more comprehensive health and family planning framework.

\section{Conclusion}

The present study concluded that high fertility behaviors were practiced collectively by just less than one-fifth of mothers in Mosul. The prevalence was significantly affected by socio-demographic and personal characteristics of couples. Effective engagement of all human resources is recommended by the present study to provide a solid support for constructing healthy fertility behaviors that are consistent with religious and social contexts; as well as for confirming the non-reproductive role of women in the society besides being home-manager, child bearer and caregiver. Health education process should embrace the risks of teenage marriage, close birth interval and have many living children.

\section{Competing interests}

The authors declare that they have no competing interests.

\section{References}

1. United Nations. Manual X: Indirect techniques for demographic estimation. New York: Department of International Economic and Social Affairs: Population Studies no. 81; 1983.

2. Gatarayiha JP, Rukundo A, Karema C, Nkusi E, Ngabo F, llibagiza D, et al. editors. Rwanda: Interim Demographic and Health Survey 2007-08. Rwanda: Ministry of Health of Rwanda, National Institute of Statistics of Rwanda and ICF Macro Calverton, Maryland, USA; 2009.

3. Mahjabeena T Khanb IA. Analyzing Bongaarts model and its applications in the context of Bangladesh. $19^{\text {th }}$ International Congress on modeling and simulation; 2011 Dec 12-16; Perth (Australia). 2011

4. Mesleh RA, Al-Aql AS, Kurdi AM. Teenage Pregnancy. Saudi Med J 2001; 22(10):864-7.

5. Strobino DM, Grason H, Minkovitz C. Charting a course for the future of women's health in the united states: concepts, findings and recommendations. Soc Sci Med 2002; 54(5):839 $-48$

6. Singh S, Darroch JE. Adolescent pregnancy and childbearing: Levels and trends in developed countries. Fam Plann Perspect 2000; 32(1):1423.

7. Casterline JB, Lazarus RT. Determinants and consequences of high fertility: a synopsis of the evidence. Ohio: Department of Sociology. Ohio State University; 2010.

8. Daniel WW. Biostatistics, a foundation for analysis in the health sciences. $8^{\text {th }}$ ed. Georgia State (USA): Wiley (John Wiley \& Sons, Inc); 2005.

9. Jakel JF, Elmore JG, Katz DL. Common research design used in epidemiology. In: Epidemiology, biostatistics and preventive medicine; 1996.

10. Chadha VK. Sample size determination in health studies. NTI Bulletin 2006; 42(3):55-62.

11. Bartlett JE, Kotrlik JW, Chadwick CH. Determining organizational research: determining appropriate sample size in survey research appropriate sample size in survey research. ITLPJ 2001; 19(1):43-50.

12. WHO. Sampling Methods and Sample Size. In: Health research methodology: a guide for training in research methods. 2nd Ed. Manila: Regional Office for the Western Pacific; 2001.

13. Greenberg R, Daniels S, Flanders W, Eley J, Boring J. Medical epidemiology. $4^{\text {th }}$ ed. Lange Basic Science; 2004.

14. I-WISH 2011. Complete survey for social and health indicators of Iraqi women. A summary report. Iraq: Ministry of Planning, Central Bureau of Statistics; 2011.

15. Fuster V. Inbreeding pattern and reproductive success in a rural community from Galicia (Spain). J Biosoc Sci 2003; 35(1):83-93.

16. Helgason A, Palsson S, Gudbjartsson DF, Kristjansson T, Stefansson K. An association between the kinship and fertility of human couples. Science 2008; 319(5864):813-6.

17. Al-Abdulkareem AA, Ballal SG. Consanguineous marriage in an urban area of Saudi Arabia: rates and adverse health effects on the offspring. J Community Health 1998; 23(1):75-83.

18. Tadmouri GO, Nair $P$, Obeid $T$, Al Ali MT, Al Khaja N, Hamamy HA. Consanguinity and reproductive health among Arabs. Reprod Health 2009; 6:17.

19. Conde-Agudelo A, Rosas-Bermúdez A, Kafury-Goeta AC. Birth Spacing and Risk of Adverse Perinatal Outcomes: A Meta-analysis. JAMA 2006; 295(15):1809-23. 
20. Makinwa-Adebusoye P, Kritz MM. Reproductive decision-making in Nigeria: An overview. Union for African Population Studies. Afr Popul Stud 1997; 12(1).

21. Mutharayappa R, Choe MK, Arnold F, Roy TK. Son preference and its effect on fertility in India. India: National Family Health Survey Subject Reports Number 3; 1997.

22. Abbasi-Shavazi MJ, Morgan SPh, HosseinChavoshi M, McDonald P. Family change and continuity in the Islamic republic of Iran: Birth control use before the first pregnancy. Iran: National Institute of Child Health and Human Development; 2007.

23. Grant JC, Bittles AH, Sullivan SG, Hussain R. Does inbreeding lead to decreased human fertility? Ann Hum Biol 2002; 29(2):111-30.

24. Vahidnia F. Case study: fertility decline in Iran. Popul Environ 2007; 28(4-5):259-66.

25. Burner B. Religiousness and fertility among Muslims in Europe, does Islam influence fertility? Oslo: Oslo and Akershus University College of Applied Sciences, Faculty of Social Sciences Oslo and Akershus University College Oslo; 2012.

26. Karim M. Changes in fertility rates among Muslims in India, Pakistan, and Bangladesh [on line]. Washington (USA): Population Reference Bureau; 2009. (Accessed November 5, 2018 at http://www.prb.org/Articles/2009/ karimpolicyseminar.aspx).

27. Khraif RM. Fertility in Saudi Arabia: levels and determinants. King Saudi University. Salvador (Brazil): XXIV General Population Conference; 2001.

28. León A. The effect of education on fertility: Evidence from compulsory schooling laws. Department of Economics, University of Pittsburgh, Pittsburgh; 2004.

29. Ayoub AS, Tuman JP, Johnson DR. The Effects of Education on Fertility in Colombia and Peru: Implications for Health and Family Planning Policies. Glob Health Gov 2007; 1(2):1-13. 